DOI: https://doi.org/10.36910/6775-2524-0560-2020-41-14

УДК: 621.391

${ }^{1}$ Мороз Борис Іванович, д.т.н., професор.

https://orcid.org/0000-0002-5625-0864

${ }^{1}$ Щербаков Артем Геннадійович, студент

${ }^{1}$ Національний технічний університет «Дніпровська політехніка»

\title{
MATHEMATICAL MODEL OF AN AUTOMATED VIDEO SURVEILLANCE SYSTEM FOR PERFORMING SPECIAL FUNCTIONS
}

\begin{abstract}
Мороз Б. І., Щербаков А. Г. Математична модель автоматизованої системи відеоспостереження для виконання спеціальних функцій. Запропоновано математичну модель автоматизованої системи відеоспостереження. Розглянуті математичні моделі окремих вузлів літального апарату: динаміка квадрокоптера, RC передатчик, RC отримувач, HD камери. Показано, що такі моделі - є найбільш ефективні для виконання ключових задач.

Ключові слова: динамічна модель, RC передатчик, RC приймач, AWGN, стабілізація відео, стерео зображення, mеan shift алгоритм.
\end{abstract}

Мороз Б. И., Щербаков А. Г. Математическая модель автоматизированной системы видеонаблюдения для выполнения специальных функций. Предложена математические модель автоматизированной системы видеонаблюдения. Рассмотрены математические модели отдельных узлов летательного аппарата: динамики квадрокоптера, RC передатчик, RC приемник, HD камеры. Показано, что такие математические модели являются наиболее эффективными для выполнения ключевых задач.

Ключевые слова: динамическая модель, RC передатчик, RC приемник, AWGN, стабилизация видео, стерео изображения, mean shift алгоритм.

B. Moroz., A. Shcherbakov. Mathematical model of an automated video surveillance system for performing special functions. The mathematical model of the automated video surveillance system is offered. Mathematical models of separate units of the aircraft are considered: quadrocopter dynamics, $\mathrm{RC}$ transmitter, $\mathrm{RC}$ receiver, HD camera. It is shown that such mathematical models are the most effective for performing key tasks.

Keywords: dynamic model, RC transmitter, RC receiver, AWGN, video stabilization, stereo image, mean shift algorithm.

Introduction and statement of the research problem. Over the past 2 years, the number of VR headsets sold has more than tripled. Every day, VR attracts the attention of more and more new users who set more and more complex tasks for developers. One of such tasks is to combine a VR system with a mobile aerial vehicle for real-time video surveillance. Companies such as Google and AT\&T Labs - Research are attempting to create an available mobile aerial vehicle system that can be controlled via a VR headset, but the companies keep their developments in the strictest confidence. Therefore, to date, there are no publicly available mathematical models for VR drones that would allow obtaining panoramic video in 360 degrees and would perform a number of special functions. Thus, the task is to synthesize a mathematical model of a drone that allows us to capture an image from a number of cameras, stabilize video, transmit data over a long distance, edit/combine together the resulting video sequence for projection onto a VR helmet.

The purpose is to propose a mathematical model of a drone, to consider mathematical models of the dynamics of a quadcopter, capturing images from cameras, converting video into an analog signal, receiving and transmitting a signal over a long distance, controlling the drone in real time.

The analysis of recent research and publications. For now, there are several scientific developments regarding our topic:

1. David Finn and Qikai Huang (Bruce Wingo) developed a mathematical model of quadcopter kinematics and dynamics, as well as trajectory control algorithms. [1]..

2. V. Kavitha and G. Balakrishnan analyzed algorithms and mathematical models to reduce gaps and imbalances in stereo images [2].

3. Li Bing considered a mathematical model of the attenuation of the signal in free space and the transmit path attenuation for an unmanned aerial vehicle [3].

4. Wilbert G. Aguilar proposed a new technique for real-time video stabilization with low computational cost, without deterioration of video quality for aerial vehicles [4].

Having considered mathematical models, we can explain the system and study the operation of various components, as well as predict further behavior. By analyzing the mathematical model, we can find a weak 
link in the system and improve it before creating a prototype. On the other hand, the experimental model may not be implemented due to the high cost of the hardware.

\section{Presentation of the main material.}

The description of the mathematical model of the drone begins with determining the state of the variables. The mathematical model of drone control is based on the laws of physics: the aspect ratio of coordinates and the basic laws of kinematics, with the help of which the control object will be described. There are several approaches to the mathematical description of the system. We will consider a common way of describing a mathematical model - through spatial and angular coordinates selected as state variables. A quadrocopter model with traction forces, angular velocities of rotation of rotors, moments of forces and a coordinate system is shown in Fig. 1.

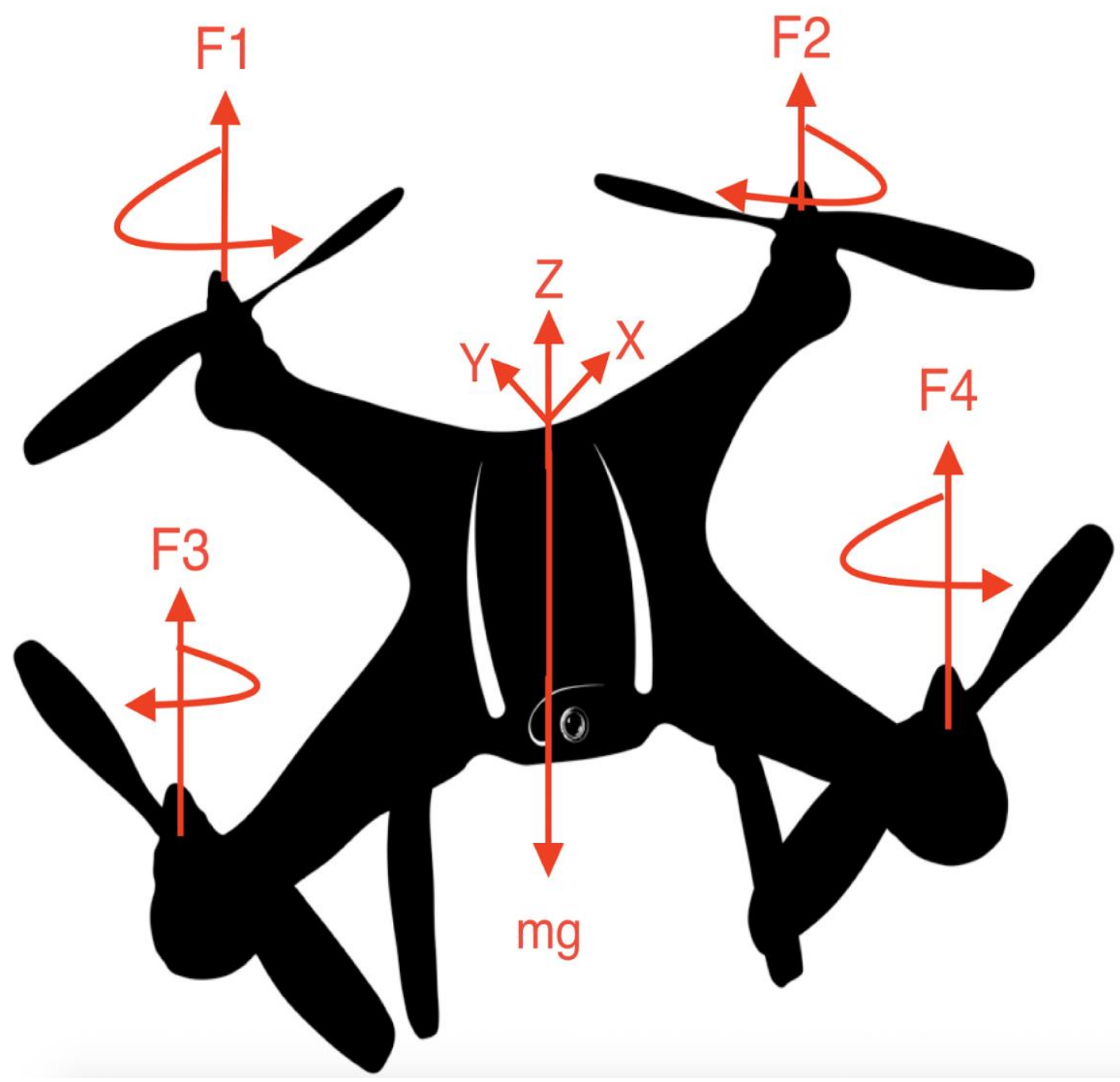

Fig. 1. Kinematic scheme of the quadcopter

The drone moves through space due to the resulting directional vector, which depends on the rotational speed of each engine. The engines create thrust and torque relative to the center of mass of the drone [5]. In the considered model of the drone, the "Cross" scheme is used.

The quadrocopter has six degrees of freedom, so we can get a mathematical system of 6 equations. The origin of the coordinate system is at the center of mass of the drone. The linear and angular velocities of the drone are represented by system (1). 


$$
J_{B}=\left[\begin{array}{l}
J_{X}, B \\
J_{Y}, B \\
J_{Z}, B
\end{array}\right], \omega=\left[\begin{array}{l}
p \\
q \\
r
\end{array}\right]
$$

The position of the quadcopter in space is characterized by the coordinates $\mathrm{x}, \mathrm{y}, \mathrm{z}$ of the vehicle's center of mass in a fixed Cartesian coordinate system and the Euler angles $\psi, \varphi, \theta$, which determine the orientation of the coordinate system associated with the areal vehicle axes with respect to the fixed coordinate system xyz [6]. The figure 2 shows a fixed coordinate system and Euler angles to describe the drone in space.

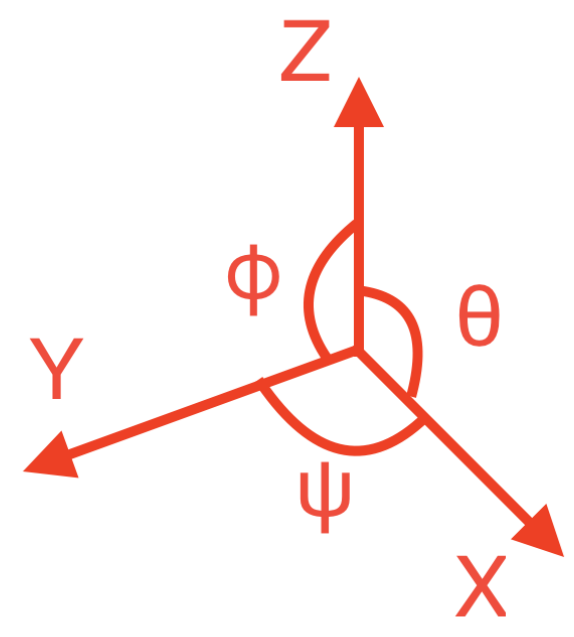

Fig. 2. Linked coordinate system

In addition, a set of vectors is used to describe the state of the quadcopter in space. For example, the linear position of the drone in a fixed coordinate system, the angular position of the quadcopter. To transform coordinates from a moving CS to a fixed one (R), a rotation matrix is used, which is a sequential multiplication of the transition matrices for each coordinate. This feature of this method is its disadvantage: if the sequence of rotation of the quadrocopter in space is changed, that is, it is first rotated not along the $\mathrm{Z}$ axis, but, for example, along the $\mathrm{Y}$ axis, then the quadrocopter will come to a completely different final position. Therefore, when choosing this method, we must adhere to the initially selected rotation order along the coordinate axes. The relationship between linear velocities in a stationary and bound coordinate system is determined by the equation (2).

$$
\xi=R \cdot V_{Q}
$$

The presented quadrocopter has a symmetric structure with 4 screws. It can be assumed that the tensor of inertia will have the form (3).

$$
J=\left[\begin{array}{ccc}
J_{x x} & 0 & 0 \\
0 & J_{y y} & 0 \\
0 & 0 & J_{z z}
\end{array}\right]
$$

The rotors rotate at an angular velocity $\omega_{i}$, creating a thrust force $F_{i}$ directed along the rotor's axis of rotation. In addition, when the rotors rotate, an aerodynamic moment $\tau_{i}$ arises, directed in the opposite direction to the angular velocity of the rotor. For the torque and traction force, simplified equations in system (4) are presented:

$$
\left\{\begin{array}{c}
F_{i}=b \cdot \omega_{i}^{2} \\
\tau_{i}=b \cdot \omega_{i}^{2}+J_{m} \cdot \dot{\omega}_{i}
\end{array}\right\},
$$


where $J_{m}$ is the moment of inertia of the motor, $\mathrm{b}$ is a coefficient of lift, $\mathrm{k}$ is a coefficient of rotation, $\mathrm{i}=1 . .4$. The summation of the thrust forces gives the total thrust $\mathrm{T}$, which is co-directional with the axis $Z_{Q}$. Thus, a vector $T_{Q}$ is obtained. It consists of a single component and describes the vector of thrust forces. The torque vector $T_{Q}$ contains the torques at all three Euler angles $\left(\tau_{\varphi}, \tau_{\theta}, \tau_{\psi}\right)$.

The Newton-Euler equation allows you to describe the dynamics of a quadcopter (as a rigid body). In a dynamic coordinate system, the dynamics of the drone can be described by an equation of the form (5).

$$
M \cdot\left(\dot{V}_{q}+v \times V_{q}\right)=R^{T} \cdot G+T_{Q}
$$

where $M$ is the total mass of the drone, $M \cdot \dot{V}_{q}$ is the force applied to accelerate the drone, $M \cdot v \times V_{q}$ is centrifugal force, $R^{T} \cdot G$ is the gravitational force.

In a static coordinate system, centrifugal force is not taken into account. Thus, the acceleration of the drone is affected by the gravitational component and the thrust vector, which are determined by the direction and force of thrust. After all the transformations, we get a system of equations, which is a mathematical description of a quadrocopter, without taking into account external influences (6).

$$
\left\{\begin{array}{c}
\ddot{x}=\frac{T}{M} \cdot\left(C_{\varphi} \cdot S_{\theta} \cdot C_{\psi}+S_{\varphi} \cdot S_{\psi}\right) \\
\ddot{y}=\frac{T}{M} \cdot\left(C_{\varphi} \cdot S_{\theta} \cdot S_{\psi}-S_{\varphi} \cdot C_{\psi}\right) \\
\ddot{z}=\frac{T}{M} \cdot C_{\varphi} \cdot C_{\theta}-g \\
\ddot{\varphi}=\frac{\left(J_{y y}+J_{z z}\right) \cdot \dot{\theta} \cdot \dot{\psi}}{J_{x x}}+\frac{\tau_{\varphi}}{J_{x x}} \\
\ddot{\theta}=\frac{\left(J_{z z}+J_{x x}\right) \cdot \dot{\varphi} \cdot \dot{\psi}}{J_{y y}}+\frac{\tau_{\theta}}{J_{y y}} \\
\ddot{\psi}=\frac{\left(J_{x x}+J_{y y}\right) \cdot \dot{\varphi} \cdot \dot{\theta}}{J_{z z}}+\frac{\tau_{\psi}}{J_{z z}}
\end{array}\right.
$$

The digital data transmission system is based on six main blocks. In the transmitter, functional blocks are responsible for modulation, encoding, message processing and data transmission over the communication channel. In the receiver, functional blocks decrypt data in the opposite direction. The main goal of a digital system is optimized message transmission, by compressing the data itself (for example, MPEG), choosing the best methods for coding and modulation in order to recover the message in the receiver with minimal loss [7]. Original data in analog form digitized into a binary sequence (information sequence). The source encoder is responsible for compressing the information sequence to provide it with the least redundancy. The compressed data is sent to the channel encoder. The channel encoder adds redundancy to the binary sequence that can be used by the receiver to filter out noise and interference that the signal collides during transmission over the communication channel. Thus, the redundancy added to the original message is intended to improve the reliability of the received data and improve the accuracy of the received signal. Therefore, the channel decoder is responsible for data integrity and assists the receiver in decoding the desired information sequence.

The digital data transmission system is responsible for the formation of a digital baseband signal on the receiver side, coding and transfer to High frequencies. In addition to signal modulation, modern devices are able to add additive white Gaussian noise (AWGN) to the signal and simulate fading. The block diagram of a digital communication transmission system is shown in Fig. 3.

At the moment, the most common is the only mathematical model for communication channels with white Gaussian noise, which is based on the use of points in the signal space. Its essence lies in the transformation of the original data vector, consisting of the symbols of the original modulation alphabet, into points of the signal space according to the selected modulation method, superimposing white Gaussian noise on the obtained values and converting the noisy points of the signal space into the vector of the original data (symbols of the original modulation alphabet) [8]. 
Transmitter

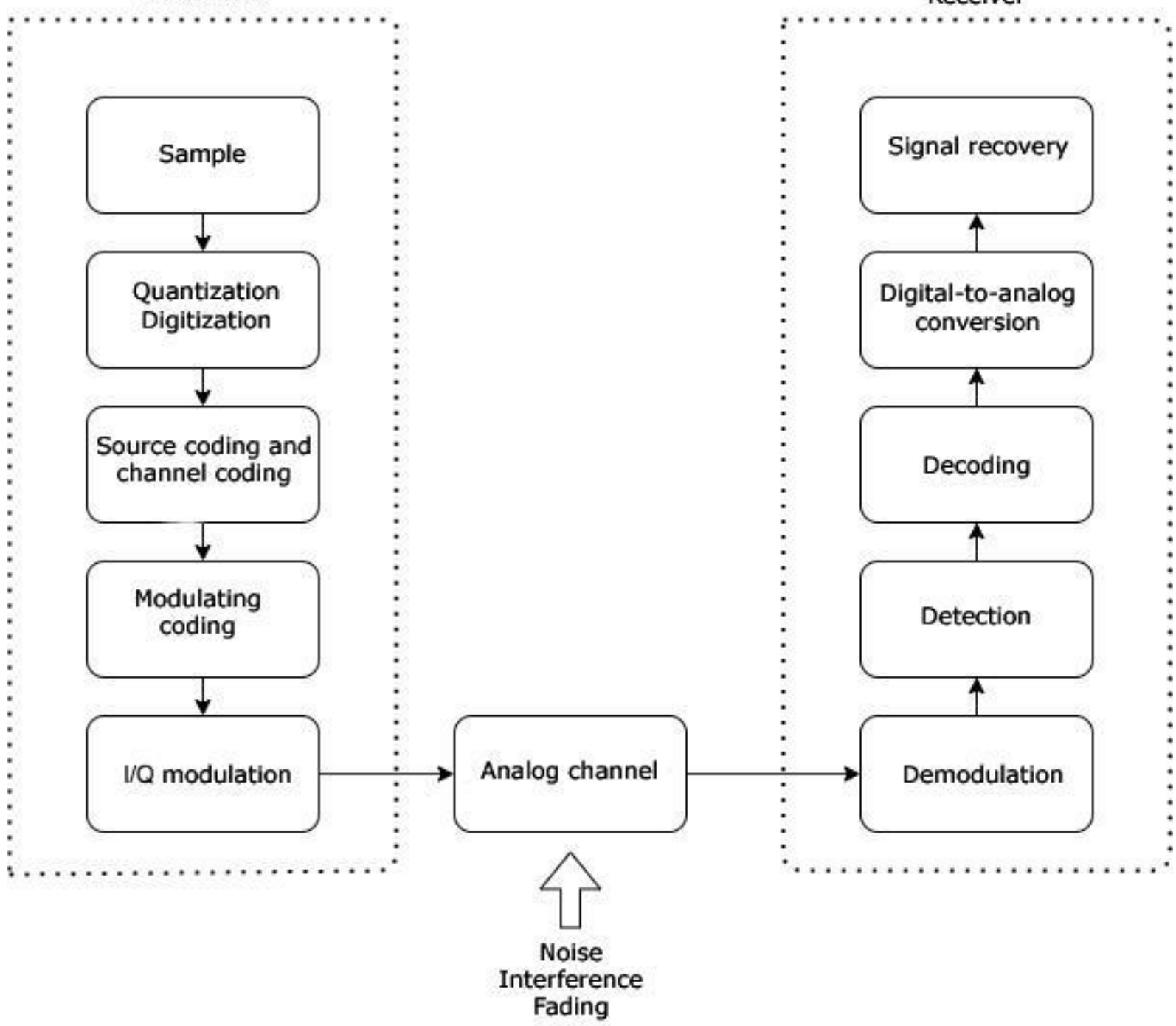

Fig. 3. The block diagram of a digital communication transmission system

Modulation of the symbol of the original modulation alphabet to a point in the signal space (7).

$$
S_{i}=\frac{2 \pi i}{e^{M \cdot j}}
$$

where $j$ is the imaginary unit, $M$ is the size of the modulation alphabet, $i$ is the symbol of the modulation alphabet in the range [0, M - 1], is a signal space point.

Superposition of white Gaussian noise on a point in the signal space (8).

$$
R_{i}=S_{i}+n,
$$

where $n$ is the complex value of white Gaussian noise, $R_{i}$ is a noisy point of the signal space,

Demodulation of a noisy point of the signal space into a symbol of the original modulation alphabet (9).

$$
x=\left[\frac{j \cdot M \cdot \ln R_{j}}{2 \pi}\right] \cdot|M|,
$$

where $j$ is the imaginary unit, $M$ is the size of the modulation alphabet, $R_{j}$ is a noisy point of the signal space. Thus, the presented mathematical model fully conveys the data transmission process with white Gaussian noise. 
Optical stabilization during video recording is considered to be more effective, however, it leads to an increase in the cost of video cameras. Software stabilization allows us to improve the quality of the video sequence already in post-production, which is an undoubted advantage if the video sequence has already been filmed and there is no binding to a particular video camera.

For dynamic scenes containing camera movement, the calculated global frame motion vector can consist of two main components: intentional movement (for example, camera panning) and unintentional movement [9]. The image correction algorithm should remove only unintentional movements, while saving the planned movement of the camera. Assuming that inadvertent camera movement during shooting corresponds to high frequency vibrations, the algorithm will use a low pass filter. Smoothing Motion Vector (SMV) is obtained by low-pass filtering that preserves the intentional movement of the camera. The proposed method calculates SMV as a first order regression equation using the formula (10).

$$
S M V_{n}=\alpha \cdot S M V_{n-1}+(1-\alpha) \cdot G M V_{n}
$$

Since the first-order low-pass filter uses little memory, it can be used in real-time systems. Motion smoothing can be adjusted by choosing an appropriate value for $\alpha$. The larger the parameter $\alpha$, the greater the smoothing factor, which in turn leads to smooth movement, but increases the delay when the camera moves deliberately. The dynamic adjustment of the parameter $\alpha$, based on the value of the global camera displacement in the last thirty frames, is calculated by the formula (11).

$$
G D i f f_{n}=\sum_{i=n-30}^{n}\left|G L V_{i}-G L V_{i-1}\right|,
$$

where $n$ is current frame number, $G L V_{i}$ is global motion vector of the shot $\mathrm{i}$. The input parameters of the fuzzy model that select the smoothing coefficient are:

a) the sum of global motion vectors modulo over the last 30 frames of the video sequence $G D$ if $f_{n}$;

b) the number of extrema as a function of global frame movement, which shows the intensity of camera shake, over the last 30 frames of the video sequence. The quality of video stabilization is directly proportional to the values of the input parameters. The larger the values of the input parameters, the larger the value of the smoothing coefficient should be selected.

After calculating the smoothing parameter $\alpha$, the smoothing vector $S M V_{n}$ is calculated by the formula (10). And the calculation of the value of the unwanted motion vector ( $U M V_{n}$, Unwanted Motion Vector) is made according to the formula (12).

$$
U M V_{n}=G M V_{n}-S M V_{n}
$$

To restore the current frame, it is necessary to change the position of its stabilized position to the vector of accumulated unintentional motion (AMVk, Accumulated Motion Vector) is calculated by the formula (13).

$$
A M V_{n}=\sum_{i=k_{f r-1}}^{n} U M V_{i},
$$

where $k_{f r-1}$ is the number of the first frame since the last scene change.

Image segmentation is the division of an image into many non-overlapping areas or objects [10]. Image segmentation is one of the main tasks of computer vision, since image analysis often begins with division into regions. The image segmentation algorithm refers to nonparametric clustering methods, which does not require a preliminary specification of the number of clusters for search [11]. The core density is estimated as the total influence of the sample elements (14).

$$
f_{h}(x)=\frac{1}{N \cdot h^{d}} \cdot \sum_{i=1}^{N} K\left(\frac{x-x_{i}}{h}\right)
$$

As a kernel for estimating the probability density $K(x)$, the classical Gauss kernel can be used (15). 


$$
K_{G} \cdot\left(\frac{x-x_{i}}{h}\right)=\exp \left(-\frac{\left\|x-x_{i}\right\|}{2 \cdot h^{2}}\right)
$$

where $h$ is a smoothing parameter.

Iterative procedure starting from point $x_{0}$, moves sequentially to the shift point $x_{k+1}=m\left(x_{k}\right)$ up to convergence to the local density maximum (16)

$$
m(x)=\frac{\sum_{i=1}^{N} x_{i} \cdot K\left(x-x_{i}\right)}{\sum_{i=1}^{N} K\left(x-x_{i}\right)}
$$

Vector $m(x)-x$ is called the "mean shift" vector, its direction coincides with the direction of the maximum density growth at the point $\mathrm{x}$.

Conclusion and prospects for further development. The article considered a dynamic model of a quadrocopter, which allows us to control the position of the drone in space by controlling the speed of the rotors. Also, a block diagram was considered and a mathematical model for converting a digital-to-analog signal for data transmission over long distances was described, taking into account white noise and interference in the air. To stabilize the video sequence, a model of a low-frequency vector with a smoothing motion vector was considered and an assessment of unwanted motion was carried out. Also, the mathematical model of the mean shift algorithm for stereoscopic segmentation of video objects is considered.

The considered mathematical models make it possible to simulate the behavior of individual parts of a quadrocopter and analyze the advantages and disadvantages of each of them, before synthesizing a single aircraft system.

In further research, it is necessary to consider a mathematical model for combining together a video sequence from several video cameras and further projecting the video sequence onto a VR headset.

\section{References}

1. Q. Huang. Mathematical Modeling of Quadcopter Dynamics [Text] / Q. Huang, D. Finn // Rose-Hulman Undergraduate Research Publications. - 2016. - № 11. - P. 1-14.

2. V. Kavitha. A Survey and Analysis of Mathematical Algorithms on Stereo Images and Its Techniques [Text] / V. Kavitha, G. Balakrishnan // Global Journal of Pure and Applied Mathematics. - 2017. - V. 13, № 9. - P. 6355-6366.

3. Li Bing. Study on Modeling of Communication Channel of UAV [Text] / Li Bing // Procedia Computer Science. - 2017. - V. 107. - P. 550-557.

4. W.G. Aguilar. Real-Time Model-Based Video Stabilization for Microaerial Vehicles [Text] / W.G. Aguilar, C. Angulo // Neural Process Lett. - V. 43, № 2. - P 459-477.

5. Image segmentation. [Electronic resource] // URL: https://ru.qwe.wiki/wiki/Image_segmentation.

6. Dr. Ali Hassan Al-Fayadh. CT Angiography Image Segmentation by Mean Shift Algorithm and Contour with Connected Components Image [Text] / Dr. Ali Hassan Al-Fayadh, Hind Rostom Mohamed, Raghad Saaheb AlShimsah // International Journal of Scientific \& Engineering Research. - 2012. - V. 3, №8. - P. 1-5.

\section{Список бібліографічних просилань.}

1. К. Габуев. Система автоматического управления беспилотного летательного аппарата [Text] / К. Габуев, В. Гонгало, Н. Кучеренко, А. Шипко // Automation technological and business - processes. - 2017. - V. 9, № 4. - Р. 57 62.

2. К. Котов. Метод управления полетом квадрокоптера в задаче сопровождения цели [Техt] / К. Котов, А. Нестеров, М. Филиппов, А. Ян // Автометрия - 2017. - V. 53, № 4. - Р. 3-10.

3. Куприянов А. Л. Математическая модель видеосистемы распознавания дорожной дорожной разметки и сигналов светофора [Text] // Наука без границ. - 2019. - V. 4, № 32. - Р. 46-53.

4 Перов, Б. Г. Анализ математических моделей каналов связи с белым гауссовым шумом [Техt] / Б. Г. Перов, В. Б. Голков, М. А. Черанёв, В. П. Полторак // Молодой ученый. - 2013. - V. 6, №53. - Р. 114-116.

5. Буряченко В.В. Стабилизация видео на основе метода соответствия блоков [Text] // Материалы международной конференция «Телевидение: передача и обработка изображений», Санкт-Петербургский государственный электротехнический университет ЛЭТИ. - 2011. - Р. 61-64. 